\title{
A review of electrical energy management techniques: supply and consumer side (industries)
}

\author{
Afua Mohamed \\ Mohamed Tariq Khan \\ Department of Electrical Engineering, Cape Peninsula University of Technology
}

\begin{abstract}
A review of electrical energy management techniques on the supply side and demand side is presented. The paper suggests that direct load control, interruptible load control, and time of use (TOU) are the main load management techniques used on the supply side (SS). The supply side authorities normally design these techniques and implement them on demand side consumers. Load management (LM) initiated on the demand side leads to valley filling and peak clipping. Power factor correction (PFC) techniques have also been analysed and presented. It has been observed that many power utilities, especially in developing countries, have neither developed nor implemented DSM for their electrical energy management. This paper proposes that the existing PFC techniques should be re-evaluated especially when loads are nonlinear. It also recommends automatic demand control methods to be used on the demand side in order to acquire optimal energy consumption. This would lead to improved reliability of the supply side and thereby reducing environmental degradation.
\end{abstract}

Keywords: electrical energy management, demandside management, maximum demand, power factor correction

\section{Introduction}

Electrical energy management (EEM) is a topic that has reached specific concern in the twenty- first century due to its contribution to economic development and environmental advancement. It has as a logical outcome and the planning of varieties of initiatives that could be deployed to reduce energy consumption. EEM maybe performed on the supply side (SS) or demand side (DS).

On the supply side, EEM is undertaken when:

- There is a growing demand (demand require- ment is higher than supply).

- There is a lack of resources (finance, energy) and EEM helps to postpone the construction a new power plant.

On the demand side, energy management is used to reduce the cost of purchasing electrical energy and the associated penalties. The techniques used for EEM are aimed at achieving valley filling, peak clipping and strategic conservation of electrical systems. Al-Shakarchi \& Abu-Zeid (2002); and Kissock \& Eger (2008) presented the techniques used to decrease the need for additional capacity and the costs involved by increased fuel on the supply side. The implementation of the techniques leads to improving off-peak valley-hours and the load factor of the system. The common load management techniques to SS or DS are presented as load shedding and restoring. There are also more exotic means such as power wheeling, the installation of energy efficient processes and equipment, the use of energy storage devices, co-generation, use of renewable energy and reactive power control. Implementation of these techniques has found a steady increase in application and meets demand side management (DSM) objectives.

In this paper, we review the techniques used for electrical energy management carried out on the supply and demand side, and recommend the appropriate methods more suitable for industrial applications.

\section{Electrical energy management: Power supply side}

The power supply side executes production and delivery of electric power. It is also responsible for supplying sufficient electric power at the acceptable standards and high level of reliability. The power utility of a vertical integrated system is normally split into four processes namely generation, transmission, distribution and retailing of electric power.

Electric power is a non-storable product, (unlike water or other type of energy that the amount col- 
lected at a certain time may be stored for future use) and hence, the amount generated at any instant should not be higher than the amount required by the demand. The generated AC supply is periodically fluctuating and is a sum of consumers' demand e.g. residential, commercial, and industrial.

Demand of electricity has been increasing worldwide and has caused electrical energy to become a scarce resource in developing countries. The electricity generated should be utilised efficiently to meet the demand of countries. This improves the reliability of the power supply system. In this regard, electrical energy management (EEM) is the cheapest action that can support the growing electricity demand and allows enough time for the utility companies to plan for investment of new generating plans.

\subsection{Energy management techniques}

Energy management embodies engineering, design, applications, utilization, and to some extent, the operation and maintenance of electric power systems for the provision of the optimal use of electrical energy without violating other international standards. Load management in utility industries is the planning and implementation of the utility activities, which are designed to influence customers to use electricity in such a way, that it produces a desired change in the utility load shape.

\section{Direct load control (DLC)}

This is the program designed to interrupt consumers' loads during the peak time by direct control of the utility power supply to individual appliances on a consumer premises. The control usually involves residential consumers. The cost benefit of DLC includes:

- Power system production cost savings.

- Power system generating capacity cost savings.

- Power system loss reduction.

Benergee (1998) presented DLC for agricultural pumps and commercial air conditioners. He defined the load management as an action that involves analysis of variations, identification of controllable loads, selection of control options and implementation of strategies. Interruptible and time of use tariff was tested and found to have a useful option for India's power supply. He further studied the nature of controlled load and set the type of control option as:

- Direct load control, utility can switch off the load directly when required.

- Interruptible load control - the utility provides advance notice to the customer for switching off their loads.

- TOU tariffs, where utility rate structure is designed according to the time.

Backer (1986) introduced the DLC carried by the Pacific Gas and Electric Company. He proposed classification of customers loads according to the size of load. Telephone, radio signal and power line were used to produce a signal that interrupted large industrial consumers. In this system, customers were required to reduce their electric demand to an emergency service load for only 10 minutes upon request. Under frequency, the relay was installed in the customer's loads, which responded very fast in the under frequency regime.

Tools for evaluation of end-use monitoring DLC programs were described by Nancy et al. (1989) namely as a duty cycle model (DCM) and demand side planning. The PC-based workstation had proven to be a viable and cost effective means of analysing the voluminous data used in the program. The duty cycle model offered an integrated approach to DLC impact analysis. This is given by:

$$
t=\frac{\text { Average load }}{\text { Connected load }}
$$

Kah-Hoe \& Sheble (1998) analysed DLC by profit based load management. The algorithm that determines the number of customers to be controlled was developed and considered under all possible control durations. Successive approximation techniques were employed. The developed model was based on the sum of controllable and non-controllable load, and was categorised into different customer load groups. They further concluded that there is a profit margin when the controllable load is scheduled. The model used to identify controllable and non-controllable load is given as:

$$
\mathrm{Tl}=\mathrm{Cl}+\mathrm{Nl}
$$

Where: $\mathrm{Cl}$ is controllable load and $\mathrm{Nl}$ is non-controllable load

Ahsan (1990) presented the impact of load management strategies on the reliability and production cost of the interconnected systems. The segmentation method was used. A model of basic approach for LM applicable to two interconnected system was developed. The basic approaches considered were the direct, indirect load control and energy storage. The study concluded that instead of increasing generating capacity, a load management scheme could be applied to the system as an alternative solution.

\section{Load management by time dependent tariffs}

In this method, load management is carried out by the influence of tariffs setting. The total cost of generating and delivering of electricity to consumers was being broken into four fundamental categories of services:

- Customer services,

- Distribution services,

- Transmission services,

- Generation services, 
Integrated utilities in regulated states set the rates to cover the costs of all services.

The electric consumers are billed as:

- Flat rate tariffs / two part tariff

- Time of use tariff (TOU)

- Spot price

In a flat rate tariff, a customer pays the same amount for electricity at any time of day.

Chamberlin \& Herman (1996) as well as Ashok \& Benergee (2001) presented load management by TOU rates. In this method, the utility provides transparent information on the electricity price at different periods to the customers to encourage off peak and discourage peak period consumption by varying price of electricity. Time of use rates provide variation of the cost of energy by season or time of day. Rates are higher during peak demand periods and lower during off-peak periods. Some utilities have made TOU rates mandatory for large customers. Savings from time of use rates vary depending on the size of the peak/off-peak price differential and the length of the peak period.

Babu (1995) developed discriminatory time of use tariffs in which the price corresponds to the marginal cost of supply. He identified that the price of electricity has a significant contribution to the LM scheme. An econometric model for electricity demand in the domestic sector was developed. Linear programming (LP) was used to set electricity tariffs.

Another type of tariff setting for LM is spot price. The message is sent to customers to indicate the price of electricity for an instant of time. A spot price scheme is appreciable if electricity price fluctuation is high and if the consumer can anticipate the price behaviour as well as being able to respond quickly when the electricity price is high or low.

\section{Dispatch load management (DLM)}

In this method, the utility make agreements with the customers on the reduction of their load for a certain time. In exchange, customers receive discounts on their electric bills. These programmes are primarily oriented towards large commercial and industrial (C\&I) customers. The number of participants is generally low, but load reductions per customer can be significant and overall load savings is substantial (Nadel, 1992). The problem of this method is the amount of actual reductions, which might be less than contracted reductions, because not all customers are able to fully shed loads during their shedding periods.

\section{Rebate program}

Rebates are a type of financial incentive offered by electric utilities over the past decade. In the residential sector, rebates have been commonly offered for the purchase of efficient appliances and compact fluorescent bulbs. In the C\&I sectors, lighting rebate programmes are most common, followed by air conditioning and motor rebate programmes. Rebate levels vary widely, from approximately 20 $100 \%$ of the cost depending on the price (Nadel, 1990; Nadel \& Geller, 1999). Another example is the DSM rebate program presented by Mthombeni, (2007).

\section{Thermal energy storage}

It is the use of thermal energy storage to store heat for space or water heating during off peak period and use at the peak time. This system is also widely used in air conditioners. The on- off switching of the storage elements was accomplished by communication technology and control as voluntary load control. A separate meter was usually used to distinguish storage loads and other loads (Leif et al., 1981)

\subsection{Other energy management measures taken by utility industries}

National energy strategies are striving towards achieving stable and reliable sources of energy to meet the demands of the individual country. Traditionally, many of these demands have been met by burning fossil fuels. In recent years, concerns on climate change have risen and call for reliable and clean energy. Many alternative energy resources have been explained and recommended as clean energy but in one way or another, they are not full utilized due to their own technological barriers.

Nuclear energy has been used successfully in a few places, but this source is not feasible without its own set of environmental concerns. Other alternative sources of energy include the use of solar energy, wind power, and biomass fuels. These sources of energy can be used in urban and rural areas. Renewable energy technologies (RETs) are attractive and environmentally sound technology options. In addition, most of renewable energy technologies are modularised and are well suited for meeting decentralized rural energy demand. Renewable energy technologies that utilize locally available resources and expertise provide employment opportunities for the locals. Finally, RETs can improve an electrical power supply system by providing energy surplus to the grid system.

\section{Electrical energy management (EEM) through consumers}

This section focuses on EEM techniques used to manage electrical energy on the demand side. It solely refers to the approaches undertaken on the consumer side, entailed to reduce their electric energy cost. EEM in demand side is the practice that deals with design, application, utilization and maintenance to optimize electrical energy consumption aimed at energy and peak demand reduction. 
The importance of EEM in industries, in terms of its energy saving potential, was highlighted by Bjorke, (1985), while Gellings, (1985) mentioned the aim of EEM initiated by supply side. Moreover, Gellings emphasized that, supply side implements energy management for the benefit of its own side. Hence, consumers are not directly benefiting from the supply side load management program whereas EEM programmes initiated by demand side techniques in production industries can bring direct profit to the industries as well as the utility system (Antonio et al., 1991).

Energy management methods are grouped in four general categories.

- House keeping measures;

- Equipment and process modification;

- Better utilization of equipment; and

- Loss reduction (IEEE std 739-1984).

Bjorke (1985) concluded that the industrial sector has good potential for achieving load management results due to the possibility of controlling large amounts of load. In order to determine controllable and non-controllable loads and the loads, which provide greater potential for demand reduction, he proposed inventory study. In addition, the adapted techniques as follows:

- Bivalent systems;

- Load priority systems;

- Energy storage in industrial process and other feasible applications; and

- Cycling group of load (On and off).

Computer software was used to monitor the operation of the system. Loads were allowed to vary as per rate schedule.

Ostadi et al (2007) proposed the model used for optimization of energy systems. Through different energy optimization methods, the possibility of reducing energy consumption has been found.

Much earlier on, Manichaikul \& Schwepper (1979) proposed a physical based industrial electric loads demand modelling. The demand of industries was analysed in detail from the stochastic aspect of the use of individual pieces of equipment and the product flow and storage structure of individual process. The mathematical model describing the two aspects was formulated. The developed model had two general steps i.e.:

i) Development of a physical load model;

ii) Combine the result from the step i with various types of economic analysis depending on the issues of interest.

The model considered the load of individual jth machine in industries as $\mathrm{P}(\mathrm{t})$ :

$$
P_{j}(t)=X_{j} r_{j} u_{j}(t)
$$

and the total plant load PT (t) was given by:

$$
P_{T}(t)=\sum_{j} P_{j}(t)
$$

Where:

$X_{j}$ represents the installed capacity rating,

$r_{j}$ represents the fraction of load on for the $\mathrm{j}^{\text {th }}$ machine,

$U_{j}(t)$ is the utilization factor,

$U_{j}(t), P(t)$ and $P_{T}(t)$ are the continuous time random process.

\subsection{Load shape change}

In order to achieve load shape change, the techniques proposed by Gellings are still viable (Gelling \& Chemberlin, 1993).

Load shedding is a term used to describe the practice of trimming peak power demand to reduce high demand penalties. It involves shifting of load from peak to off peak period. The load shape objective is one of the DSM objectives that are used for peak shaving.

Ashok \& Benergee (2001) introduced load management applications for the industrial sector. Load shifting was considered as the best method for reducing customer demand during peak period. The load shifting techniques were used to select the load or processes, which can be shifted/ rescheduled. The method used in this study was the use of economic incentives and disincentives offered through the electric rate structure.

An energy intensive load and their consumption characteristics in industry were analysed. The proposed method was to shift load in such away that loads are diverted from a peak period to an off peak period, whereby shaving the peak and filling the valley.

The mathematical model was developed to allow optimization of electrical energy used. Formulation of the model was based on integer linear programming for minimizing electricity cost by scheduling the loads while satisfying the process storage and production constraints. The model was also used to analyze energy consumed in response to different tariffs. The objective function was to reduce energy cost.

The parameters that must be considered in formulation of the mathematical model used for optimization of the system includes development of the entire time horizon, ' $\mathrm{H}$ ' of the interval and constraints as:

$$
\begin{gathered}
\sum_{i=1}^{N} t_{i}=H, \text { for the total intervals } \mathrm{N}, \\
\text { in the time horizon }
\end{gathered}
$$

The constraints involved in this problem were given in the form of mathematical equations as follows:

\section{Production constraints}

$$
\sum_{i=1}^{N} \sum_{m=1}^{M} P_{m i} * t_{m i} * I_{m i} \geq Q
$$


Where:

$M$ is the total number of machines processing or producing final out put,

$Q$ is minimum production

$P_{m i}$ is production rate of machine $\mathrm{m}$, in the interval

Storage of the system should be at a limited level The process loads with storage facility and maximum capacity limitations is given by:

$$
\sum_{i=1}^{T}\left[\sum_{m=1}^{M} P_{m i} \times t_{m i} \times I_{m i}-\sum_{r=1}^{R} q_{r i} \times t_{r i} \times I_{r i}\right] \leq S_{m} \quad 7
$$

$T=1$ to $N$

$S_{m}$ is maximum storage capacity

The main aim of the model was to limit the system to operate at maximum demand; hence, the

$$
\sum_{m=1}^{M}\left(\frac{k_{m i}}{p f_{m i}}\right) * I_{m i} \leq K V A_{i} \begin{aligned}
& \text { peak demitation was } \\
& \text { given by: }
\end{aligned}
$$

8

Where:

$K V A$ is the maximum demand limit

$K_{m i}$ is electrical power input of individual machine $\mathrm{m}$ and

$p f_{m i}$ power factor

\section{Objective function}

The objective function was to minimize cost of elec-

$\operatorname{Min} . \sum_{i=1}^{N} \sum_{m=1}^{M}\left(k_{m i} * I_{m i} * t_{m i}\right) * C_{i} \quad \begin{array}{ll}\text { trical energy } & \text { through energy }\end{array}$ consumption

optimization. Where $C_{i}$ is the cost of energy for the interval $\mathrm{i}$, the objective function is given by:

\section{9}

Ashok (2006) presented a load model, which incorporates the characteristics of batch type loads related to any type of process industry. The model was coupled with an optimization process utilizing integer linear programming for minimizing the total electricity cost. A TOU tariff was used to compare the effectiveness of the model.

A demand model was reported for Japan's industry. The designed model reflected the actual areas for energy consumption. From the model, it was then possible to detect all potential areas for energy reductions. The reduction was achieved by designing intelligent systems in combination with highly efficient technologies. The concept of Best Available Technologies (BAT) was implemented in the industrial, residential and commercial sectors of
Japan.

Khosid (1998) reported active load management and its associated mathematical model for a load-controlled consumer (LCC). The model assumed that each system has some LM facility that can reduce energy consumption and prevent system shut down when an emergency occurs.

The developed model determined technical potentials and cost of the active load management for an industrial consumer with continuous production. It was assumed that LCC has a storage unit between each production section. Power limitation of some shops leads to the decrease in their output, however, it does not affect the normal work of the adjacent section that use products from the preceding section. The reduction strategy was determined based on minimal power consumption that allows the section to perform its basic operation.

This model was designed to solve optimal distribution of power limitations between LCC's shops and maximum time of power limitation when LCC reduced the power demand.

Mathews et al. (2008) proposed real-time energy management in the cement industry and developed the procedures for identifying DSM opportunities. These procedures included data gathering and refining, simulation of silo levels and material flows for energy optimization.

A control philosophy was developed to realize the DSM potentials. The developed Control software utilizes an existing supervisory control and data acquisition (SCADA) system of the factory. Automatic dynamic simulation of the raw mill system was conducted in a real-time environment. The control system was equipped with a computerized logging system that logs the hourly material flow from the limestone bins to the raw mills. Historical data was used to determine baselines for the two raw mill sections. Simulation of the milling schedule was required to comply with below mentioned constraints:

- The Eskom Mega Flex tariffs must be used for the savings calculation.

- The electricity cost must be minimized during the peak times.

- The maximum electrical load cannot exceed the installed capacity.

- The correct material flows or silo capacities must be known.

The results obtained from the simulation provided a more accurate description of the actual material flow through the raw mill systems than the energy simulation alone. Finally, the study shows that the milling systems can be main contributors to demand side management initiatives.

\subsection{Power factor correction}

Power factor (pf) is the ratio between the $\mathrm{kW}$ and the KVA drawn by an electrical load. It is a measure 
of how effectively the current is being converted into useful work.

Many instruments and analysis techniques for evaluating the power factor were devised only to consider the phase shift component of the power factor. Phase shift is measured in degrees, but it is equivalent to time. This component of the power factor is called the displacement power factor (DPF). Utilities that impose low power factor penalties tend to measure DPF only (IEEE std 141-1993)

Inductive loads, mainly induction motors, cause a low power factor in industries. Inductive loads require reactive power for the creation of magnetizing current that facilitates magnetic field in the required circuit. Reactive power drawn by inductive loads increases the amount of apparent power in the distribution system.

\subsubsection{Benefits of improving power factor}

- Smaller utility bills

- Increase internal electrical system capacity.

- Improve voltage drop at the point of use, (voltages below equipment rating reduces efficiency, increases current, and reduces starting torque in motors).

- Improve voltage regulation.

- Improved system efficiency.

\subsubsection{Power factor corrections strategies}

In many electrical systems, capacitors are used to correct the power factor. Alternative ways of improving the power factor include:

- Replacement of over-sized motors with standard or high efficiency motors of the right horsepower.

- Shutdown idle running motors.

- Avoid operation of equipment above its rated voltage.

In modern industries, there is an issue of harmonics caused by nonlinear loads; hence, to depend on capacitor correction only, might not help much. More research on harmonic filters is needed.

\subsection{Electrical load management (ELM) process}

The load management process includes:

\section{Load character assessment}

Load characteristics are to be defined by measurement and analysis of data. Statistical parameters, load duration curves, duty cycles and load-profiles etc. are used to define the characteristic of the load. Techniques such as statistical regression and time series are used to define the load model of the plant. Statistical regression gives the energy model of the analysed load as a function of various variables.

\section{Load control impact assessment}

In order to asses the impact of load control, a model capable of predicting load behaviour with and without load control is to be developed. The models should be able to respond under all possible load control initiatives. It has also used in identifying control strategies, which maximize the impact of over energy consumption.

The next step is the implementation of the load control and verification, which are normally achieved by post implementation measurements of the output data.

\section{Role of demand side management}

Demand side management (DSM) activities are those involving action on demand or the customer side of the electric meter, either direct caused or indirectly stimulated by the utility aiming at managing consumption of energy, in order to optimize available energy generated and resources. These are load management, strategic conservation, and strategic growth (Gelling \& Chemberlin, 1993). The DSM of any utility company is developed with specific objectives such as:

- Planning objectives

- Load shape objectives

The planning objectives of many utilities including South Africa's Eskom are given (NER, 2000):

- Minimize future revenue requirements.

- Reduce future utility capital expenditures.

- Increase opportunities for all customers to reduce their bills.

- Improve financial performance.

- Minimize investor's risk.

- Maximize planning flexibility.

These goals are strategic if they are established to guide activities in the long term. The aims of the load shape objectives are to implement peak clipping, valley filling and load shifting by using the DSM activities stipulated by Gellings. DSM options that are potential for efficiency improvement have to be identified, evaluated and implemented.

Load levelling (peak clipping and valley filling) is used to smooth out the peaks and dips in energy demand by reducing energy consumption during the peak period. Valley filling is the process of making an energy production and delivery system to be more efficient by encouraging additional energy use during off peak periods.

\section{Discussion}

The electrical energy management techniques implemented by supply or demand side have been reviewed. The Energy management on the supply side is normally performed for the benefit of the power supply company but the actions are taken on the demand side. In some cases, there is an agreement between the supply side and customers. The drawback of EEM on the supply side does not pro- 
vide enough profit to the demand side (it does not give opportunity for many customers to plan for supply interruption).

Direct load control is commonly applied to domestic consumers. Price signal (spot price) is one of the potential means of electrical energy management but this system is not viable especially to the utility industry of which most of its consumers have variable load profiles e.g. domestic consumers. Such kind of utility industries are found in developing countries and their maximum demand occurs between 17:30-21:00.

Another challenge to the introduction of generalised spot pricing is the need to replace the entire metering system, which of course, requires tremendous investment and legislation. The method is therefore not appropriate to many developing countries.

Load management on the consumer side has proven to bring direct benefits. A review of many research materials revealed that most of the EEM techniques developed in demand side management have not clearly provided load control methods. The commonly used technique is load shedding by TOU tariff. Automatic power demand controllers with optimum load shedding are proposed for peak demand management. The controllers should be able to analyze and detect predicted maximum demand. The system is to be programmed to recognize which loads have priority and which loads are non-essential.

\section{Conclusions}

In this paper, electrical load management techniques on the supply side and demand side have been reviewed. On the supply side, this review found that there are three main methods used for load management i.e. direct load control, interruptible load control and time of use (TOU). These methods were developed on the supply side and implemented on the demand side, aiming at a reduction of system peak demand and improving the reliability of power supply.

Load management initiated by customers on the demand side was based on implementation of strategies that lead to reduction of electrical energy consumption.

Power factor improvement has also been considered as one of the load management (LM) actions. Correcting pf brings the demand saving on the demand side and improves the reliability of the power supply. Through this review, it has been discovered that many industries are still implementing a capacitor bank for power factor correction. In doing so, the presence of nonlinear load is not considered. This paper proposes that the capability of the capacitor PFC method needs to be evaluated, especially in nonlinear loads and further research on alternative methods or modifications of the exist- ing PFC are to be worked out so as to achieve more energy saving.

The paper also proposes automatic demand control techniques to be used for appropriate demand management and recommends more research on load management strategies on the consumer side. This should be done in order to minimize the energy cost baring (demand side), improve the reliability of the supply side, and reduce environmental degradation.

This review should be taken as a challenge to the power supply industry especially in developing countries, which have not yet considered or developed active DSM programs. DSM can improve the capacity addition and hence reduce environmental degradation.

\section{References}

Ahsan Q, 1990, 'Load management: impacts on the reliability and production costs of interconnected systems', Electrical Power and Energy System, Vol.12, No. 4, pp. 275-262.

AL-Shakarchi M.R.G. and ABU-Zeid N.SH, 2002, 'A Study of Load Management by Direct Control for Jordan's Electrical Power System' Journal of Science \& Technology, Vol.7 No. 2.

Antonio Barreiro, Jose Ferreira, Carlos Abreu and Michael Blanks, 1991, 'Energy management for rational electricity use- Reducing cost and consumption at SECIL's Outao Cement Plant' IEEE transaction on industrial applications, Vol.27, No. 3, pp. 398-405.

Ashok S, 2006, 'Peak- loads management in steel plants' Applied energy, Vol. 83, pp. 413-428.

Ashok, S and Banerjee R, 2001, 'An optimization mode for industrial load management' IEEE Transactions on Power Systems, Vol. 16, no. 4, pp. 879-884.

Babu Ram, 1995, 'Tariff and load Management: Post privatisation study of the U.k electricity supply industry' IEEE Transactions on Power System, Vol.10, No. 2, pp. 1111-1117.

Backer D. L, 1986, 'load management direct control fact or simulation' IEEE transaction on Power system, Vol. PWRS-1, No. 1, pp.82-88.

Benergee Ragan, 1998, 'Load management in the Indian power sector using US experience' Energy, Vol.23, No. 11, pp. 961-972.

Bjorke C. O, 1985, 'Load Management Applications for Industrial Loads' IEEE Transactions on Power Apparatus and Systems, Vol. PAS-104, No. 8, pp. 2058-2062.

Chamberlin J. H, Herman P. M. 1996, 'How much DSM is really there? A market perspective' Energy Policy, Vol. 24, No. 4, pp. 323-330.

Channele D. 'U.S Electric utility Demand side management: Trends and analysis' [online]. www.eia.doe. gove/cneaf/pubs-html.dsm [26/04/2008].

Gellings, C. W\& Chamberlin, J. H, 1993, 'Demand-Side 
Management: Concepts and Methods', Second Edition, the Fairmont Press.

Kah-Hoe Ng, Gerald B. Sheble, 1998, 'Direct load control- A profit - based Load management using linear programming', IEEE Transaction on power systems, Vol.13, No. 2. pp. 688-695.

Kissock J Kelly. and Carl Eger, 2008, 'Measuring industrial energy savings' Applied Energy Vol. 85, No. 5, pp. 347-361.

Khosid S, 1998, 'A mathematical model of load-controlled consumer for an active loadmanagement' Electrotechnical Conference, MELECON 98, 9th Mediterranean Vol. 2, No. 18-20 pp. 1076 - 1079.

Leif Isakson, Fred S. and Nelson W,1981, 'Bibliography on load management', IEEE Transactions on Power Apparatus Vol. PAS-100, No. 5, pp. 2597- 2599.

Manichaikul Y and Schwepper F. C, 1979, 'Physical based industrial electric load modelling' IEEE transaction on power systems, Vol. PAS98 No. 4, pp 14391445.

Mathews E. H, Kleingeld .M, Van der Bijl J and Jordaan $\mathrm{N}, 2008$, 'Real-time energy management in the cement industry' EE Publisher, pp. 74-80.

Mthombeni Tsakani Lotten, 2007, 'Energy efficient motor systems for ESKOM Demand Side Management' Proceedings of ICUE, Cape Town South Africa.

Nadel Steven, 1992, 'Utility Demand-Side Management Experience and Potential- A Critical Review' Annual Review of Energy and the Environment, Vol. 17, pp 507-535.

Nadel Steven \& Geller Howard, 1999, 'Utility DSM-What have we learned? Where are we going?' Energy policy, Vol. 24, No. 4, pp. 289-302.

Nancy E. Ryan, John T. Power, 1989, 'Generalizing direct load program analysis: Implementation of the duty cycle approach', IEEE transactions on power systems, Vol. 4, No. 1, pp. 293-299.

National Electricity Regulator (NER), 2000, South Africa.

Received 8 September 2008; revised 10 June 2009 